Disponível em:

http://editora.unoesc.edu.br/index.php/race

RACE, Joaçaba, v. 17, n. 1, p. 365-388, jan./abr. 2018

\title{
A ESTRUTURA DE CAPITAL DE EMPRESAS DE PEQUENA DIMENSÃO EM PORTUGAL: UMA ABORDAGEM SEGUNDO AS TEORIAS DO TRADE-OFF E DA PECKING-ORDER
}

The small firms'capital structure in Portugal: an approach to the Trade-off and Peckingorder theories

Claudio Eduardo Ramos Camfield

E-mail: claudiocamfield@hotmail.com

Mestre em Engenharia de Produção pela Universidade Federal de Santa Maria; Doutorando em Gestão na Universidade da Beira Interior de Portugal;

Professor Adjunto na Universidade Federal de Santa Maria - Campus Palmeira das Missões.

Endereço para contato: Avenida Independência, 3751, Vista Alegre, 98300-000, Palmeira das Missões, Rio Grande do Sul, Brasil.

Guilhermina Maria da Silva Freitas

E-mail: freitas.guilhermina@gmail.com Mestre em Contabilidade e Finanças Empresariais pela Universidade Aberta de Lisboa de Portugal; Doutoranda em Gestão na Universidade da Beira Interior de Portugal; Professora Adjunta no Instituto Politécnico de Coimbra - Business School.

Marco Rafael Fernandes Correia E-mail: marcorafaelcorreia@gmail.com Mestre em Gestão pela Universidade da Beira Interior de Portugal; Doutorando em Gestão na Universidade da Beira Interior de Portugal; Engenheiro Eletromecânico.

Zélia Serrasqueiro

E-mail: zelia@ubi.pt Doutora em Gestão pela Universidade da Beira Interior de Portugal; Professora Catedrática no Departamento de Gestão e Economia da Universidade da Beira Interior de Portugal. 
Resumo

No corrente estudo analisaram-se os fatores explicativos das decisões de estrutura de capital das Pequenas Empresas (PEs) portuguesas, dado a estrutura de capital destas ter um interesse relevante ao nível econômico-social geral. Neste trabalho centrou-se na teoria Pecking-order (POT) e na teoria do Trade-off, considerando-as mutuamente explicativas e complementares, para avaliar o papel de um conjunto de fatores divididos em três níveis: os internos à empresa, os ligados ao mercado e os ligados ao sistema fiscal. Com base em uma amostra de 2.329 PEs portuguesas, os dados foram sujeitos a uma regressão multivariada. Os resultados obtidos mostram que a rentabilidade, a liquidez e a idade têm um impacto negativo e significativo no endividamento, evidenciando a importância dos princípios da teoria Pecking-order para as decisões de estrutura de capital das empresas portuguesas de menor dimensão. O relacionamento positivo entre a variável dimensão da empresa e o endividamento dá algum suporte à importância da teoria do Trade-off em contexto das decisões de estrutura de capital das pequenas empresas.

Palavras-chave: Teoria Pecking-order. Teoria do Trade-off. Endividamento. Portugal.

\section{Abstract}

The present study analyzes the explanatory factors of the capital structure decisions of the Portuguese Small Companies (PEs), given that the capital structure of these companies has a relevant interest in the general economic-social level. This paper focuses on the Peckingorder (POT) theory and the Trade-off theory, considering them mutually explanatory and complementary, to evaluate the role of a set of factors divided into three levels: the internal to the company, market and the tax system. Based on a sample of 2.329 portuguese PEs, data were submitted to a multivariate regression. The results obtained show that profitability, liquidity and age have a significant impact on indebtedness, evidencing the importance of the principles of the pecking-order theory for the capital structure decisions of smaller portuguese firms. The positive relationship between the firm's variable size and indebtedness supports the importance of Trade-off theory in the context of the capital structure decisions of the companies analyzed. Keywords: Pecking-order theory. Trade-off theory. Debt. Portugal.

\section{INTRODUÇÃO}

O debate entre a Pecking-order theory (POT) e a teoria do Trade-off apresenta, frequentemente, essas teorias como mutuamente exclusivas tendo sido apresentadas para a resolução de problemas distintos e para empresas distintas, contudo, a sucessão de estudos não tem sido consistente com um único caminho. Pelo contrário, 
vários estudos mostram a coexistência entre as duas formas de abordagem relatadas, como, por exemplo, Mukherjee e Mahakud (2012).

Essas teorias farão sentido quando aplicadas a Pequenas Empresas (PEs) ou o seu poder explicativo é apenas para empresas de maior dimensão? A resposta a essa questão é dada, em contexto das empresas italianas por Bontempi (2002), que mostra que as empresas preferem as fontes de financiamento interno quando se está em foco o curto prazo, e não o longo prazo. Gracia e Mira (2008), em um estudo para a economia espanhola, reconhecem alguma proximidade das Pequenas e Médias Empresas (PMEs) relativamente aos princípios da POT, sendo forte essa evidência quando as empresas procuram se alavancar por meio de fundos externos, mesmo em desvantagem com as grandes empresas, relativamente aos custos de transação.

Cotei e Farhat (2009) não evidenciam a separação entre uma e outra teoria, coordenando-se em razão do objetivo das empresas, pelo fato de que se a teoria do Trade-off é importante para a definição da percentagem de dívida face aos fundos próprios, a POT explica a determinação da forma como é feito o ajustamento dos fundos próprios face à dívida, no que se refere às PEs dos Estados Unidos.

Relativamente às empresas portuguesas, ainda que de região periférica, Serrasqueiro e Caetano (2015) concluem que as teorias POT e Trade-off não são mutuamente exclusivas, explicando simultaneamente o comportamento das empresas relativamente ao seu nível de endividamento. González e González (2012) e Serrasqueiro e Nunes (2012) referem que essas duas teorias são necessárias para a compreensão das estruturas de capital das PEs durante o seu ciclo de vida.

Nesse contexto, neste estudo teve-se por objetivo evidenciar, por meio de uma análise empírica, as relações de duas principais teorias ligadas ao endividamento nas empresas de pequena dimensão em Portugal.

Além desta seção inicial que compreendeu a introdução do estudo, na segunda seção trata-se do referencial teórico sobre a POT e a teoria do Trade-off. Na terceira seção apresenta-se a metodologia, detalhando as variáveis de investigação e a amostra deste estudo. Na quarta seção apresentam-se os resultados e na quinta é feita uma discussão destes. Finalmente, na sexta seção apresentam-se as conclusões, limitações e sugestões futuras para investigações nesta área.

\section{REFERENCIAL TEÓRICO}

Na área de investigação em finanças corporativas, muitos trabalhos empíricos vêm sendo desenvolvidos sobre os fatores que levam as empresas a estabelecerem 
uma determinada estrutura de capital. Nesse sentido, uma das principais teorias sobre estrutura de capital foi proposta por Myers (1984) conhecida como Pecking-order theory (POT). Frank e Goyal (2003) defendem que os princípios da POT se destacam pela sua capacidade explicativa das decisões de estrutura de capital das empresas.

A POT fundamenta-se na ideia de assimetria de informação entre gestores e investidores. Myers (1984) sugere que uma empresa segue os princípios dessa teoria quando, para financiar os seus investimentos, seleciona o financiamento interno em detrimento do externo. Sob a insuficiência de financiamento interno, a empresa é obrigada a recorrer a financiamento externo, optando pelo recurso à dívida, relegando a emissão de ações para última opção. De acordo com a POT, as empresas selecionam as fontes de financiamento, seguindo uma ordem hierárquica nas preferências por fontes de financiamento, recorrendo em primeiro lugar a fontes de financiamento internas e, em seguida, a fontes de financiamento externas de maior facilidade de acesso e menor custo, e, por último, a fontes externas de maior dificuldade de acesso e maior custo.

Myers (1984) mostra que a POT indica uma ordem hierárquica na seleção de fontes de financiamento, segundo as seguintes preferências: em primeiro lugar, as empresas selecionam lucros retidos, seguindo-se o recurso a endividamento, e, por fim, a emissão de novas ações ordinárias.

Aggarwal e Kyaw (2010) corroboram o argumento de Myers e Majluf (1984) quando afirmam que, por causa dos custos de transação e assimetria de informação, as empresas procuram se autofinanciar, em primeiro lugar com lucros retidos e em seguida com recurso à dívida sem risco; depois, recorrendo à dívida com risco; e, por último, à emissão de ações junto a investidores externos à empresa.

Sistematizando essas ideias, a POT proposta por Myers (1984) e Myers e Majluf (1984) pressupõe a seguinte ordem hierárquica de preferências na seleção de fontes de financiamento:

a) as empresas preferem financiar seus investimentos com lucros retidos do que com outras fontes de fundos;

b) por causa dessa preferência, as empresas procuram adaptar suas políticas de dividendos para fazerem face às suas necessidades de investimento;

c) como existe relutância em alterar substancialmente a política de dividendos, e os fluxos de caixa e as necessidades financiamento associadas aos investimentos são flutuantes, os lucros retidos podem ser maiores ou menores que as necessidades de investimento; por isso, se as empresas 
possuírem free cash flows, tenderão a pagar suas dívidas antes de recomprar ações;

d) se precisarem de financiamento extra, as empresas tenderão, em primeiro lugar, a emitir dívida sem risco, nesse caso, empréstimos do sistema bancário e títulos de dívida não convertível;

e) somente, em último recurso, as empresas recorrem à emissão de títulos de dívida convertível e de ações ordinárias.

Seguindo essa linha de raciocínio, em que se coloca a base da POT sob a teoria da informação assimétrica proposta por Myers e Majluf (1984), a hierarquia da estrutura de capital decorre da assimetria de informação entre gestores e investidores, em que os gestores tendem a emitir novas ações quando os preços estão sobrevalorizados, beneficiando, assim, os antigos acionistas. Cientes dessa possibilidade, novos acionistas podem exigir um desconto sobre o preço das ações, como requisito à aquisição de ações. Myers (1984) sugere que as empresas que procuram reduzir os custos de informação assimétrica têm uma preferência pelos vários tipos de fontes de financiamento. Também Kayo e Kimura (2011) corroboram inferindo que as empresas que têm boas oportunidades de investimento, mas sem financiamento interno, tendem a recorrer à dívida para financiar seus projetos, o que pode levar a níveis de alta alavancagem.

Em uma versão simples do modelo da POT, as empresas com elevadas oportunidades de investimento e de crescimento estão previstas para terem alta alavancagem (sob a condição de que os investimentos superem o financiamento interno). Em uma versão mais complexa dessa teoria, as empresas com elevadas oportunidades de crescimento futuro poderão reduzir o nível de alavancagem no momento presente, de forma a assegurarem capacidade de endividamento futura e também possibilidade de financiamento dos investimentos futuros (AGGARWAL; KYAW, 2010).

A POT também prevê que as empresas com elevadas oportunidades de crescimento futuro devem pagar dividendos mais baixos. Aggarwal e Kyaw (2010) acrescentam que Shyam-Sunder e Myers (1999) introduziram um modelo de déficit de financiamento para testar a hipótese de hierarquia da estrutura de capital da empresa. Aqueles autores argumentam que, com exceção de empresas muito próximas do estado de sobre-endividamento, a POT prevê que os déficits financeiros das empresas serão inteiramente financiados com base em novas emissões de dívida. Portanto, pode-se esperar uma relação positiva entre o déficit de financiamento e a alavancagem, assumindo que as empresas ainda estão abaixo do nível de sobre-endividamento. 
Myers (1984) também destaca que, no modelo POT, as empresas não possuem metas para o seu nível endividamento. As empresas não têm nenhum interesse em aumentar o nível de endividamento quando os fluxos de caixa são positivos e suficientes para financiar, com baixo risco, os futuros investimentos. Portanto, espera-se que o endividamento decresça, enquanto os investimentos não excederem os lucros.

Por fim, Myers (1984) corrobora sobre a opção da empresa em pagar dividendos, em que a POT não explica as razões que levam as empresas a pagarem dividendos, porém, quando decidem pagar, o modelo pode impactar tal decisão. Dividendos devem ser pagos pelas empresas mais lucrativas, considerando que pode ser difícil para as empresas financiarem novos investimentos; pagar dividendos é menos atrativo para empresas menos lucrativas e alavancadas, portanto, os dividendos apresentam-se negativamente relacionados com as oportunidades de investimento e endividamento.

O sistema financeiro também parece influenciar as decisões de estrutura de capital. Dessa forma, nos países com um sistema financeiro baseado no sistema bancário, como é o caso dos países da União Europeia, os bancos são a principal fonte externa de financiamento. No entanto, nos países com um sistema financeiro centrado no mercado de capitais, como é o caso dos EUA e da Inglaterra, o mercado bolsista é a principal fonte externa de financiamento, o que se verifica em contexto de empresas cotadas (YOTI; SHENG-CHU; WEN-CHENG, 2012), e igualmente em empresas de pequena e de média dimensões (ANTONIOU; GUNEY; PAUDYAL, 2008).

Relativamente à teoria Trade-off, Frank e Goyal (2003) e Hovakimian, Kayhan e Titman (2011) argumentam que em conformidade com os princípios dessa teoria a estrutura de capital tem subjacente um Trade-off entre benefícios fiscais e custos de falência e de agência associados ao endividamento.

De acordo com Gracia e Mira (2008) na teoria Trade-off as empresas procuram obter uma estrutura de capital ótima, ponderando as vantagens e desvantagens de uma dívida adicional. Para Gracia e Mira (2008) as vantagens dessa teoria estão justamente na inclusão de pagamentos de juros, os quais podem ser deduzidos do imposto sobre a empresa e gerar poupança fiscal. Entretanto, como desvantagens dessa teoria, tem-se que a dívida inclui o custo potencial do estresse financeiro e os custos de agência decorrentes entre os dirigentes da empresa e os credores. Se a estrutura de capital ideal for alcançada, os benefícios e os custos da dívida se compensam e o equilíbrio é alcançado. Nesse sentido, Myers (1984) mostra que a abordagem de Trade-off implica a taxa de endividamento real da empresa voltando para um alvo ou nível ótimo.

Segundo Hackbarth, Hennessy e Leland (2007), os princípios da teoria do Trade-off têm subjacente que uma estrutura ótima de capital para as empresas de 
pequena dimensão implica um financiamento exclusivamente com recurso à dívida bancária, em razão das limitações de acesso a fontes externas e alternativas de financiamento. As empresas de maior dimensão, por terem uma estrutura de capitais mais robusta e acesso a fontes alternativas externas de financiamento, usam um misto de dívida bancária e dívida de mercado.

Ainda tendo em atenção a dimensão da empresa, Sheikh e Qureshi (2014) referem que as empresas de maior dimensão tendem a ter maior nível de endividamento em razão da sua capacidade de diversificar o risco, e as empresas com maior nível de ativos tangíveis podem recorrer mais a fundos externos do que as empresas com maior nível de ativos intangíveis que implicam risco. Esses relacionamentos vão de encontro aos princípios da teoria do Trade-off, sendo que as empresas com maior capacidade de prestar garantias têm maior probabilidade de obter empréstimos solicitados.

\section{METODOLOGIA}

Neste estudo tem-se como base uma pesquisa de caráter quantitativo, requerendo a coleta de dados secundários que foram sujeitos à análise estatística por meio do recurso ao package de estatística SPSS.

\subsection{VARIÁVEIS DE INVESTIGAÇÃO}

Para este estudo se escolheu o endividamento como variável dependente representativa da estrutura de capital. Para variáveis de investigação como fatores determinantes da estrutura de capital, foram escolhidas as seguintes variáveis, segundo três grupos:

\section{Primeiro grupo - Variáveis explicativas relativas aos fatores internos à} empresa:

- A dimensão da empresa como determinante da sua estrutura de capital, porque condiciona a opacidade informacional e a sua reputação;

- A liquidez é outra variável muito referida pelos diferentes estudos já realizados porque se uma empresa apresenta boa liquidez poderá ter fundos excedentários e cash-flows livres pelo fato de que o recurso a endividamento se apresenta como uma 
forma de reduzir os impostos, mas também como uma forma de reduzir a sua dependência de fundos externos e também os seus custos de falência;

- A tangibilidade é descrita na literatura como uma variável que deve suportar o endividamento, uma vez que as empresas que apresentem maiores índices de tangibilidade poderão recorrer a mais dívida porque apresentam maiores garantias aos prestamistas, e, nessa medida, obter reduções no pagamento de impostos;

- A rentabilidade, porque é espectável que empresas mais rentáveis necessitem recorrer menos a fundos externos, o que, de acordo com a POT, significaria estruturas de endividamento mais leves;

- Idade associada ao fato de as empresas estarem há mais tempo no mercado, tendo, dessa forma, já dado provas no mercado, tornando-se menos opaca e apresentando maiores garantias aos seus empréstimos. De acordo com a POT, essas empresas podem apresentar-se mais alavancadas.

\section{Segundo grupo - Variáveis explicativas relativas aos fatores associados ao mercado:}

- Oportunidade de crescimento é uma variável que suporta a realização de investimentos aumentando a necessidade de fundos; se as empresas não detiverem esses fundos terão que recorrer a financiamento externo, pelo fato de que maiores oportunidades de crescimento poderão estar associadas a estruturas de endividamento mais pesadas.

Terceiro grupo - Variáveis explicativas relativas aos fatores associados ao sistema fiscal:

- Taxa efetiva de imposto, pois segundo a teoria do Trade-off as empresas podem optar por ter estruturas de capital com grande peso do endividamento porque reduzem o montante de impostos a pagar;

- Outros benefícios fiscais porque podem permitir à empresa a poupança de impostos.

\subsection{AMOSTRA E DADOS}

Este estudo enquadra-se na investigação quantitativa, passando pela coleta de dados secundários que foram sujeitos à análise estatística por meio do recurso ao 
package de estatística SPSS. No presente estudo foram usados os dados coletados a partir do banco de dados AMADEUS, fornecidos pelo Bureau Van Dijk’s. Este contém informações econômico-financeiras para as empresas europeias.

No estudo atual, as empresas que compõem a amostra para a pesquisa têm de cumprir a definição estabelecida pela Comissão Europeia para as Pequenas Empresas (Recomendação n. 2.003/361/CE) (JORNAL OFICIAL DA UNIÃO EUROPEIA, 2003), segundo o qual, uma unidade de negócios é considerada uma pequena empresa quando: emprega menos de 50 pessoas; e o seu volume de negócios ou balanço total anual não excede $€ 10$ milhões. A amostra-base deste estudo representa os dados de 2.329 PEs portuguesas ao longo de cinco anos em um total de 11.645 observações.

Todas as empresas apresentam dados para o período em análise (2007-2011) para todas as variáveis analisadas. As empresas integram as seções A até S excluindo a seção K (atividades financeiras) e a seção O (Administração Pública e Defesa; Segurança Social Obrigatória), conforme a Tabela 1, representando, de forma adequada, a realidade portuguesa:

Tabela 1 - Distribuição das empresas da amostra pelas seções da CAE

\begin{tabular}{|c|c|c|c|}
\hline \multirow{2}{*}{$\begin{array}{l}\text { Seção } \\
\text { CAE }\end{array}$} & \multirow{2}{*}{ Designação } & \multicolumn{2}{|c|}{ Observações } \\
\hline & & N. & $\%$ \\
\hline a & Agricultura, produção animal, caça, floresta e pesca & 435 & 3,74 \\
\hline b & Indústrias extrativas & 70 & 0,60 \\
\hline c & Indústrias transformadoras & 2070 & 17,78 \\
\hline $\mathrm{d}$ & Eletricidade, gás, vapor de água quente e fria e ar frio & 15 & 0,13 \\
\hline e & $\begin{array}{l}\text { Captação, tratamento e distribuição de água, saneamento, gestão } \\
\text { de resíduos e de despoluição }\end{array}$ & 40 & 0,34 \\
\hline $\mathrm{f}$ & Construção & 385 & 3,31 \\
\hline g & $\begin{array}{l}\text { Comércio por grosso e a retalho, reparação de veículos automó- } \\
\text { veis e motociclos }\end{array}$ & 5075 & 43,58 \\
\hline $\mathrm{h}$ & Transporte e armazenagem & 225 & 1,93 \\
\hline $\mathrm{i}$ & Alojamento, restauração e similares & 1375 & 11,81 \\
\hline $\mathrm{j}$ & Atividade de informação e comunicação & 295 & 2,53 \\
\hline 1 & Atividades imobiliárias & 135 & 1,16 \\
\hline $\mathrm{m}$ & Atividades de consultoria, científicas, técnicas e similares & 675 & 5,80 \\
\hline $\mathrm{n}$ & Atividades administrativas e dos serviços de apoio & 285 & 2,45 \\
\hline $\mathrm{p}$ & Educação & 155 & 1,33 \\
\hline $\mathrm{q}$ & Atividades de saúde humana e apoio social & 250 & 2,15 \\
\hline $\mathrm{r}$ & Atividades artísticas, de espetáculos, desportivas e recreativas & 45 & 0,39 \\
\hline $\mathrm{s}$ & outras atividades de serviços & 115 & 0,99 \\
\hline total & & 11645 & 100 \\
\hline
\end{tabular}

Fonte: os autores. 
O maior número de empresas pertence à seção $\mathrm{G}$ - Comércio por grosso e a retalho, reparação de veículos automóveis e motociclos, seguida da seção C - Indústrias transformadoras e da secção I - Alojamento, restauração e similares, acompanhando a estrutura da economia portuguesa, suportada pelas pequenas empresas de comércio, da indústria transformadora e da restauração.

\section{RESULTADOS}

As estatísticas descritivas das variáveis integrantes do estudo, relativamente às medidas de tendência central (média e mediana), de dispersão (variância, desvio padrão e amplitude) e de relação entre estas e o coeficiente de variação apresentam-se na Tabela 2:

Tabela 2 - Medidas estatísticas das variáveis em estudo

\begin{tabular}{lrrrrrrr}
\hline Variáveis & N & Minimum & Maximum & Mean & $\begin{array}{c}\text { Std. } \\
\text { Deviation }\end{array}$ & Variance & \multicolumn{1}{c}{$\begin{array}{c}\text { Coef. } \\
\text { Variação }\end{array}$} \\
\hline ENDtotal1 & 11645 & 0,00 & 1,00 & 0,62 & 0,22 & 0,05 & 35,21 \\
DIM2 & 11645 & 0,80 & 4,42 & 2,81 & 0,53 & 0,28 & 18,90 \\
LIQUID3 & 11645 & $-0,74$ & 0,98 & 0,11 & 0,22 & 0,05 & 199,35 \\
TANG4 & 11645 & 0,00 & 0,99 & 0,41 & 0,25 & 0,06 & 61,73 \\
ROA5 & 11645 & $-1,35$ & 0,81 & 0,04 & 0,09 & 0,01 & 220,61 \\
GO6 & 11645 & $-0,86$ & 58,82 & 0,10 & 0,76 & 0,58 & 752,03 \\
TEFI7 & 11645 & $-117,06$ & 375,75 & 0,21 & 4,21 & 17,73 & 2016,69 \\
OBF8 & 11645 & 0,00 & 1,29 & 0,05 & 0,05 & 0,00 & 99,91 \\
AGE(In)9 & 11645 & 0,00 & 4,51 & 2,71 & 0,71 & 0,51 & 26,32 \\
\hline Fonte: 0S autos & & & & & & &
\end{tabular}

Fonte: os autores.

Notas: Endividamento Total1; Dimensão da empresa²; Liquidez ${ }^{3}$; Tangibilidade; Rentabilidade do ativo total $^{5}$; Taxa da oportunidade de crescimento ${ }^{6}$; Taxa efetiva de imposto ${ }^{7}$; Outros benefícios fiscais; Idade da empresa logaritmizada ${ }^{9}$.

Da análise do quadro pode-se verificar que as variáveis se apresentam muito heterogêneas, o que seria de se esperar em uma amostra que integra empresas de diferentes setores industriais, dimensões e enquadramentos fiscais. A variável DIM apresenta-se como a mais homogênea com um valor médio de 2,81 e um desvio padrão de 0,53, seguida da idade (AGE), cujo valor médio logaritmizado de 2,71 corresponde à idade de 15 anos. Todas as outras variáveis se apresentam muito heterogêneas. 
Tendo por objetivo neste trabalho saber em que medida as variáveis escolhidas permitem explicar a estrutura de capital das PEs portuguesas, utilizou-se uma regressão linear para se obterem informações sobre a importância e a relação das variáveis preditoras no endividamento total dessas empresas.

Nas Tabelas 3 e 4, apresentam-se os resultados das regressões multivariadas, recorrendo-se ao método stepwise:

Tabela 3 - Dados relevantes do modelo de regressão linear

\begin{tabular}{|c|c|c|c|c|}
\hline Variável & $\begin{array}{l}\text { Coeficiente de } \\
\text { regressão }\end{array}$ & $\begin{array}{c}\text { Diagnóstico de } \\
\text { colinearidade } \\
\text { (VIF) }\end{array}$ & $\begin{array}{c}\text { Adjusted R } \\
\text { Quadrado }\end{array}$ & $\begin{array}{c}\text { Anova } \\
\text { (p) }\end{array}$ \\
\hline Constante & 0,640 & --- & \multirow{6}{*}{$12,7 \%$} & \multirow{6}{*}{0,000} \\
\hline AGE(In) & $-0,080$ & 1,068 & & \\
\hline DIM & 0,081 & 1,038 & & \\
\hline ROA & $-0,426$ & 1,032 & & \\
\hline LIQUID & $-0,114$ & 1,020 & & \\
\hline GO & 0,011 & 1,022 & & \\
\hline
\end{tabular}

Fonte: os autores.

Da análise mais pormenorizada, verifica-se a capacidade preditora altamente significativa, apresentando o teste ANOVA um valor de $\mathrm{p}=0,000$.

Igualmente importa perceber se as variáveis integrantes da análise apresentam problemas de multicolinearidade, estando essa resposta conferida pela leitura do indicador de Variance Inflation Factor (VIF), que ao apresentar todos os seus valores muito inferiores a 10, permite concluir pela não existência de multicolinearidade entre as variáveis que compõem o modelo.

Foram também verificados os pressupostos de uma análise dessa natureza, não se tendo verificado problemas quanto à normalidade dos resíduos, à homocedasticidade e à linearidade dos coeficientes de regressão; pelo recurso ao histograma, Scatterplot e P-Plot, tem-se resultados espectáveis levando-se em conta a dimensão da amostra (11.645 observações).

O modelo de regressão foi construído em cinco passos, tendo assumido como primeira variável preditora a AGE(ln), seguida da DIM, do ROA e da LIQUID, e considerando no passo 5 também a GO.

Os coeficientes encontrados podem ser considerados adequados à construção da equação de regressão seguinte: 


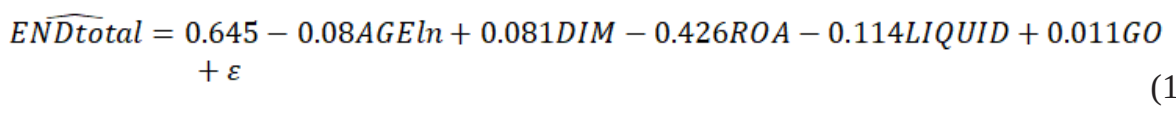

Sendo:

ENDtotal - Rácio de endividamento total;

AGE(ln) - Idade da empresa logaritmizada;

DIM - Dimensão da empresa medida pelo ativo total logaritmizado;

ROA - Rentabilidade do ativo total;

LIQUID - Rácio da liquidez da empresa;

GO - Taxa da oportunidade de crescimento da empresa;

$\varepsilon-$ Erro estimado.

Da análise da equação de regressão, as variáveis ROA, LIQUID e AGEln que a integram têm uma relação negativa com o ENDtotal da empresa. A ROA apresenta um peso muito maior que as restantes, sendo seguido da LIQUID e por fim da AGE(ln). Dessa forma, as empresas mais velhas, mais lucrativas e com uma LIQUID maior parecem apresentar um nível de ENDtotal menor. As variáveis DIM e GO apresentam uma relação direta com a variável ENDtotal, assim, uma empresa com maior nível de ativos e com mais oportunidades de crescimento apresenta um nível de ENDtotal maior. Em conjunto, as variáveis incluídas no modelo explicam 12,7\% da variância apresentada pelo ENDtotal.

Testados todos os outros métodos de regressão, verifica-se a mesma capacidade explicativa para a variância da variável predita. O poder explicativo das variáveis preditoras resultantes da regressão passo a passo apenas se altera quando se utiliza o método de entrada de todas as variáveis, considerando, para além das variáveis já referidas, a TANG e a OBF, que ainda apresentando coeficientes muito próximos de zero, não alteram de forma relevante a equação de regressão expressa, como se pode verificar na Tabela 4: 
Tabela 4 - Dados da regressão - método Enter vs Stepwise

\begin{tabular}{lcc}
\hline \multirow{2}{*}{ Variáveis preditoras } & \multicolumn{2}{c}{ Método de Regressão } \\
& ENTER & STEPWISE \\
\hline (Constant) & 0,641 & 0,640 \\
DIM & 0,81 & 0,081 \\
LIQUID & $-0,117$ & $-0,114$ \\
TANG & $-0,009$ & 0,000 \\
ROA & $-0,429$ & $-0,426$ \\
GO & 0,011 & 0,011 \\
TEFI & 0,000 & 0,000 \\
OBF & 0,032 & 0,000 \\
AGE(In) & $-0,080$ & $-0,080$ \\
\hline Fonte: 0s autores. & &
\end{tabular}

Fonte: os autores.

O método de regressão “ENTER” possui igualmente uma capacidade preditora altamente significativa, apresentando o teste ANOVA um valor de $p=0.000$; igualmente não possui problemas de multicolinearidade, ao apresentar todos os seus valores muito inferiores a 10 .

Em face da análise pormenorizada dos dois métodos e apresentando o método stepwise valores de colinearidade inferiores aos do método enter, considera-se a equação gerada pelo método stepwise como adequadamente preditora para o comportamento da variável ENDtotal.

\section{DISCUSSÃO DOS RESULTADOS}

Analisada a equação de regressão, observa-se que nem todas as variáveis testadas apresentam poder preditivo, estando, nesse caso, a tangibilidade (TANG), a taxa efetiva de imposto (TEFI) e outros benefícios fiscais (OBF).

A variável AGE (idade) apresenta uma relação indireta com o endividamento total, ainda que com uma intensidade muito pouco relevante. A consideração dessa variável em estudos dessa natureza não é consensual, já que o número de anos da 
empresa não indica, de forma direta, a fase do ciclo de vida em que a empresa se encontra, como fazem notar La Rocca, La Rocca e Cariola (2011) e Fong (2011).

A dimensão da empresa é normalmente apresentada como tendo uma relação direta com o endividamento, pelo fato de que quanto maior for a empresa, maior será o seu nível de endividamento. Os resultados do corrente estudo corroboram os resultados de estudos prévios que identificaram um relacionamento positivo entre a variável dimensão e o nível de endividamento.

De acordo com Titman e Wessels (1988), as empresas de maior dimensão tendem a apresentar maior nível de endividamento, dado serem empresas com maior nível de diversificação de atividades, diminuindo o risco de falência. Nesse estudo, ainda que apresentando um coeficiente de regressão muito pouco relevante, $8,1 \%$, verifica-se um relacionamento positivo entre a dimensão e o endividamento, corroborando as assumpções da teoria do Trade-off. Esse resultado corrobora os resultados de estudos realizados, em contexto das PEs italianas (LA ROCCA; LA ROCCA; CARIOLA, 2011), assim como em contexto das empresas Brasileiras (NAKAMURA; MARTIN; FORTE; CARVALHO FILHO; COSTA; AMARAL, 2007; BASTOS; NAKAMURA, 2009; KAVESKI, POLITELO; DA SILVA, 2013; MANOEL et al., 2016).

A liquidez é apontada pela teoria Trade-off como tendo uma relação direta com o endividamento total, contudo, isso não foi verificado neste estudo. A liquidez apresentou uma relação inversa (-11,7\%) com a variável, assim, as PEs portuguesas com maior grau de liquidez apresentam níveis de endividamento menores. Este resultado está de acordo com os princípios da POT, segundo os quais existe uma relação negativa entre liquidez e endividamento. Dessa forma, as empresas que apresentam maior nível de liquidez são menos propensas ao recurso a financiamento externo. Adicionalmente, o resultado do estudo corrente vai de encontro ao resultado de Bastos e Nakamura (2009), no qual a liquidez das empresas brasileiras e chilenas está negativamente relacionada com o endividamento total, de curto e de longo prazos contábeis. Contrariamente, aqueles autores, para as empresas mexicanas identificaram um relacionamento negativo entre liquidez e endividamento total e de curto prazo. Ainda, Nakamura et al. (2007) e Kaveski et al. (2015) apuraram uma relação negativa e significativa entre a liquidez e o endividamento, o que parece ser demonstrativo do cenário econômico brasileiro, que convive com a escassez de recursos e de altas taxas de juro.

A rentabilidade apresenta, no estudo corrente, uma relação indireta de grande intensidade, sendo que a variável explicativa do modelo tem maior coeficiente, e, portanto, impacto de maior magnitude no endividamento. Assim, as PEs portuguesas com níveis elevados de rentabilidade diminuem os seus níveis de endividamento. 
Esse resultado está de acordo com os princípios da POT que prevê que as empresas preferem financiamento interno em detrimento de dívida. Essa relação inversa entre rentabilidade e endividamento é identificada em contexto de empresas de menor dimensão, evidenciando a preferência por financiamento interno em razão dos seus menores custos (LA ROCCA; LA ROCCA; CARIOLA, 2011).

Salienta-se, também, que a variável rentabilidade, com efeito significativo e negativo (-42,6\%), traz um indicativo de que quanto maior a rentabilidade da empresa, menor a utilização de dívida como forma de financiar investimentos, apoiando a teoria Pecking-order, e corroborando os resultados de estudos anteriores no Brasil (NAKAMURA et al., 2007; BASTOS; NAKAMURA, 2009; KAVESKI; POLITELO; DA SILVA, 2013; CORREA; BASSO; NAKAMURA, 2013; KAVESKI et al., 2015; MANOEL et al., 2016).

Relativamente à variável tangibilidade, segundo a teoria do Trade-off, quanto maior for a proporção de ativos tangíveis, maior será o endividamento, pois os ativos tangíveis mostram a capacidade de a empresa prestar garantias aos credores. Adicionalmente, também a POT prevê um relacionamento positivo entre tangibilidade e endividamento, dado que os ativos tangíveis podem ser prestados como garantias aos credores, reduzindo-se os problemas de assimetria de informação e de agência entre as partes (BRITO; CORRAR; BATISTELLA, 2007; PEROBELLI; FAMÁ, 2002).

Entre as variáveis inerentes às características das empresas e que foram excluídas da regressão, a tangibilidade não era esperada. Uma justificação para os resultados obtidos para as PEs portuguesas é o fato de os seus ativos tangíveis serem constituídos por elementos não adequados à constituição de garantias perante os credores. Além disso, as PEs portuguesas têm um elevado peso da dívida de curto prazo na dívida total (FARINHA; FÉLIX, 2014). Adicionalmente, a dívida de curto prazo é concedida sem exigência de garantias por parte dos credores. Assim, o provável elevado peso da dívida de curto prazo no endividamento total das PEs portuguesas pode justificar a falta de significância estatística do relacionamento entre tangibilidade e endividamento identificada no estudo corrente.

Resultado idêntico foi obtido em estudos brasileiros (CORREA; BASSO; NAKAMURA, 2013; DOS PRAZERES et al., 2015), em que a tangibilidade não se mostrou estatisticamente significativa, o que pode sinalizar fragilidade dessa variável, dependendo do contexto em que for analisada.

Relativamente à variável oportunidades de crescimento, observa-se nos resultados deste estudo que tem poder explicativo e apresenta uma relação positiva e de fraca intensidade $(11,0)$. Essa relação apresenta-se de acordo com o esperado, dado 
que a necessidade de fundos para investimento obriga as empresas a recorrerem à dívida, na ausência de fundos internos, para implementarem as oportunidades de crescimento se não detiverem esses fundos. Assim, maiores oportunidades de crescimento poderão estar associadas a estruturas de capitais com um peso elevado do endividamento. O coeficiente da variável oportunidades de crescimento não é relevante, o que contraria o verificado por La Rocca, La Rocca e Cariola (2011) para a economia italiana. O resultado obtido neste estudo pode representar a volatilidade crescente existente em tempos de crise, pela não certeza da sustentabilidade dessas oportunidades de crescimento, bem como alguma falta de conhecimento econômico-financeiro dos empresários das PEs em Portugal.

Os estudos realizados anteriormente, em contexto brasileiro, apresentaram resultados diversos; alguns encontraram uma relação positiva entre o crescimento e o endividamento (BRITO; CORRAR; BATISTELLA, 2007; DOS PRAZERES et al., 2015, MANOEL et al., 2016), confirmando os princípios da POT. Porém, outros estudos identificaram uma relação negativa entre as variáveis crescimento e endividamento, corroborando os princípios da teoria Trade-off (BRITO; CORRAR; BATISTELLA, 2007; NAKAMURA et al., 2007). Ressalta-se que na visão dos autores mencionados se esperava uma relação negativa, visto que na $P O T$ se pressupõe uma relação negativa, dado que as oportunidades de crescimento levantam risco para os credores que dificultam as condições de acesso ao crédito, tendo um efeito negativo no nível de endividamento. Por outro lado, com base na teoria do Trade-off, tem-se que essa relação deve ser negativa em decorrência do risco que as empresas em crescimento correm por possuírem um maior risco de falência em razão da volatilidade de seus lucros (DOS PRAZERES et al., 2015).

Quando se analisam os resultados obtidos para as variáveis representativas dos fatores fiscais incluídos na análise, as variáveis TEFI e OBF, conclui-se que o modelo de regressão encontrado não os considera como explicativos do endividamento total. Esses resultados não são consistentes com os resultados obtidos por Jong, Kabir e Nguyen (2008), que concluem que aqueles fatores não explicam o grau de alavancagem das empresas portuguesas. Como justificação para esse fato, poderá estar a falta de lucratividade das empresas portuguesas que, a avaliar pelas estatísticas descritivas da variável ROA, apresentam-se de uma forma muito heterogênea e em que mais de $20 \%$ das empresas apresentam uma rentabilidade inferior ou igual a zero e apenas cerca de 30\% apresentam, como valor para essa variável, um indicador superior a 5\%. Em presença da diminuta base de incidência dos impostos, o estímulo de poupança é desnecessário, pelo fato de que as considerações das possibilidades de poupança não 
são equacionadas; relativamente aos outros benefícios fiscais, a opacidade do sistema fiscal associado à falta de conhecimentos dos empresários torna a existência desses benefícios quase desconhecida.

Os resultados encontrados permitem perceber que as variáveis consideradas como possíveis preditoras do endividamento total das PEs portuguesas, ainda que apresentando uma capacidade preditora altamente significativa, explicam apenas 12,7\% da variância da variável endividamento, pelo fato de que deverão acrescentar variáveis que encerrem outros fatores determinantes do endividamento das empresas.

De forma breve, os resultados obtidos neste estudo mostram que as variáveis com um relacionamento estatisticamente significativo e negativo com o endividamento são a rentabilidade, a liquidez e a idade, evidenciando que as PEs portuguesas seguem os princípios da POT nas decisões de estrutura de capital. No entanto, o relacionamento positivo entre oportunidades de crescimento e o endividamento também corrobora os princípios da POT. Em conformidade com essa teoria, boas oportunidades de crescimento poderão levar o recurso à dívida, quando a empresa não dispõe de financiamento interno suficiente para financiar as suas oportunidades de investimento. A teoria do Trade-off encontra algum suporte neste estudo, pois se verifica uma relação positiva entre a dimensão e o endividamento, evidenciando que as empresas de maior dimensão têm maior capacidade de endividamento, o que pode ser em decorrência do menor risco de falência que representam para os credores.

Fatores relativos ao nível de desenvolvimento de um país são apresentados como possíveis determinantes do nível de endividamento das empresas, nesse sentido, pronunciam-se Rajan e Zingales (1995), Demirgüç-Kunt e Maksimovic (1999), Palacín-Sánchez, Ramírez-Herrera e Di Pietro (2013), Booth et al., (2001), Bokpin (2009) e Baltaci e Ayaydin (2014).

Vários autores identificam a indústria, em que a empresa se insere, como um fator explicativo da estrutura de capitais da empresa, como referem Harris e Raviv (1991) e Magnus et al. (2008), mostrando que existem diferenças significativas no nível de endividamento entre as diferentes indústrias em que as empresas estão inseridas.

\section{CONCLUSÕES, LIMITAÇÕES E SUGESTÕES PARA INVESTIGAÇÃO FUTURA}

No presente estudo teve-se por objetivo evidenciar, por meio de uma análise empírica, as relações de duas principais teorias, Pecking-order e Trade-off, ligadas ao endividamento nas empresas de pequena dimensão em Portugal. Para alcançar este 
objetivo, reuniram-se dados para uma amostra de 2.329 PEs portuguesas para o período 2007-2011. Para a realização deste estudo foi escolhido um conjunto de variáveis, tendo-se verificado que nem todas apresentam poder explicativo para o nível de endividamento das Pequenas Empresas portuguesas. As variáveis preditoras são a rentabilidade, a liquidez e a idade, as quais apresentam uma relação negativa com o nível de endividamento das PEs portuguesas. As variáveis dimensão e as oportunidades de crescimento relacionam-se positivamente com o nível de endividamento, embora apresentando intensidade muito fraca.

As variáveis identificadas neste estudo, como não explicativas do nível de endividamento, são a tangibilidade (TANG), a taxa efetiva de imposto (TEFI) e outros benefícios fiscais (OBF).

Relativamente à variável tangibilidade (TANG), uma justificativa para o baixo poder explicativo pode estar vinculada a duas questões: características dos recursos tangíveis das empresas de pequena dimensão em Portugal, e, ainda, por essas empresas apresentarem dívida de curto prazo com alto peso no endividamento total, sendo que os credores não exigem colaterais como contrapartida do crédito de curto prazo.

Concernente ao conjunto restante das variáveis não explicativas, pode-se observar que estas integram os efeitos fiscais no modelo ou seja, a taxa efetiva de imposto (TEFI) e outros benefícios fiscais (OBF). Uma justificativa para essas variáveis não contribuírem para a explicação do modelo pode estar na falta de planejamento fiscal das PEs portuguesas, o que repercute nas suas decisões de financiamento. Tal fato está certamente associado à baixa lucratividade dessas empresas.

O fato de o modelo proposto para a busca de explicações do endividamento das empresas de pequena dimensão de Portugal não ter apresentado uma boa capacidade explicativa (12,7\%) pode ser em razão de que deve ser melhorado. Nesse sentido, impõe-se a necessidade de se incluir no modelo de regressão outras variáveis que possam ajudar a explicar os restantes $87,3 \%$ do endividamento. A proposta de inclusão de novas variáveis prende-se à necessidade de representatividade de outros fatores explicativos designadamente, à fase do ciclo de vida da empresa, à estrutura do sistema financeiro, ao sistema institucional e à indústria em que a empresa se insere.

Várias questões ficaram por responder, entre elas, analisar possíveis diferenças entre as empresas pertencentes a indústrias muito distintas. A resposta a essas questões constitui sugestões para investigação futura visando contribuir para o debate a respeito da aplicação das teorias de estrutura de capital às PEs portuguesas. 


\section{REFERÊNCIAS}

AGGARWAL, R.; KYAW, N. Capital structure, dividend policy, and multinationality: Theory versus empirical evidence. International Review of Financial Analysis, v. 19.2, p. 140-150, 2010.

ANTONIOU, A.; GUNEY, Y.; PAUDYAL, K. The determinants of capital structure: capital market-oriented versus bank-oriented institutions. Journal of financial and quantitative analysis, v. 43.01, p. 59-92, 2008.

BALTACI, N.; AYAYDIN, H. Firm, Country and Macroeconomic Determinants of Capital Structure: Evidence from Turkish Banking Sector. Emerging Markets Journal, v. 3.3, p. 46-58, 2014.

BASTOS, D.; NAKAMURA, W. Determinantes da estrutura de capital das companhias abertas no Brasil, México e Chile no período 2001-2006. Revista Contabilidade \& Finanças, v. 20, n. 50, p. 75-94, maio/ago. 2009.

BOKPIN, G. Macroeconomic development and capital structure decisions of firms: Evidence from emerging market economies. Studies in economics and finance, $\mathrm{v}$. 26.2, p. 129-142, 2009.

BONTEMPI, M. The dynamic specification of the modified pecking order theory: its relevance to Italy. Empirical Economics, v. 27.1, p. 1-22, 2002.

BOOTH, L. et al. Capital structures in developing countries. The Journal of Finance, v. 56.1, p. 87-130, 2001.

BRITO, G.; CORRAR, L.; BATISTELLA, F. Fatores determinantes da estrutura de capital das maiores empresas que atuam no Brasil. Revista de Contabilidade e Finanças - USP, v. 43, p. 9-19, 2007.

CORREA, C.; BASSO, L.; NAKAMURA, W. A Estrutura de Capital das Maiores Empresas Brasileiras: Análise Empírica das Teorias de Pecking Order e Trade-Off Usando Panel Data. Revista de Administração Mackenzie, v. 14, n. 4, 2013.

COTEI, C.; FARHAT, J. The trade-off theory and the pecking order theory: are they mutually exclusive? North American Journal of Finance and Banking Research, v. 3, p. 1-16, 2009. 
DEMIRGÜÇ-KUNT, A.; MAKSIMOVIC, V. Institutions, financial markets, and firm debt maturity. Journal of Financial Economics, v. 54.3, p. 295-336, 1999.

DOS PRAZERES, R. et al. Telecomunicações Brasileiro. Contabilidade, Gestão e Governança, v. 18, n. 2, 2015.

FARINHA, L.; FÉLIX, S. Uma análise de restrições de financiamento às PME Portuguesas. Artigos de Estabilidade Financeira do Banco de Portugal, v. 3, 2014.

FONG, S. Strategic management accounting of social networking site service company in China. Journal of Technology Management in China, v. 6.2, p. 125-139, 2011.

FRANK, M.; GOYAL, V. Testing the pecking order theory of capital structure. Journal of Financial Economics, v. 67.2, p. 217-248, 2003.

GONZÁLEZ, V.; GONZÁLEZ, F. Firm size and capital structure: evidence using dynamic panel data. Applied Economics, v. 44, p. 4745-4754, 2012.

GRACIA, J.; MIRA, F. Testing Trade-off and Pecking Order Theories Financing SMEs. Small Business Economics, v. 31, p. 117-136, 2008.

HACKBARTH, D.; HENNESSY, C.; LELAND, H. Can the trade-off theory explain debt structure? Review of Financial Studies, v. 20.5, p. 1389-1428, 2007.

HARRIS, M.; RAVIV, A. The theory of capital structure. The Journal of Finance, v. 46.1, p. 297-355, 1991.

HOVAKIMIAN, A.; KAYHAN, A.; TITMAN, S. Are Corporate Default Probabilities Consistent with the Static Trade-off Theory? The Review of Financial Studies, v. 25.2, p. 315-340, 2011.

JONG, A.; KABIR, R.; NGUYEN, T. Capital structure around the world: The roles of firm-and country-specific determinants. Journal of Banking \& Finance, v. 32.9, p. 1954-1969, 2008.

JORNAL OFICIAL DA UNIÃO EUROPEIA. Recomendação n. 2.003/361/CE, Portugal, 2003. Disponível em: <https://www.iapmei.pt/getattachment/PRODUTOS-E-SERVICOS/Qualificacao-Certificacao/Certificacao-PME/Recomendacao-daComissao-2003-361-CE.pdf.aspx>. Acesso em: 20 jul. 2017. 
KAVESKI, I. et al. Determinantes da estrutura de capital das empresas de tecnologia das informações brasileiras. Revista Iberoamericana de Ciencia, Tecnología e Sociedad, Buenos Aires, v. 29, n. 10, p. 235-262, mayo 2015.

KAVESKI, I.; POLITELO, L.; DA SILVA, T. Determinantes da estrutura de capital das empresas brasileiras pertencentes ao Índice do Setor Industrial da BM\&FBovespa. In: CONGRESSO BRASILEIRO DE CUSTOS - ABC, 20., Uberlândia. Anais... Uberlândia, 2013.

KAYO, E.; KIMURA, H. Hierarchical determinants of capital structure. Journal of Banking \& Finance, v. 35.2, p. 358-371, 2011.

LA ROCCA, M.; LA ROCCA, T.; CARIOLA, A. Capital structure decisions during a firm's life cycle. Small Business Economics, v. 37.1, p. 107-130, 2011.

MAGNUS, T. et al. Capital Structure Across Industries. International Journal of the Economics of Business, v. 15. 2, p. 181-200, 2008.

MANOEL, S. Et al. Determinantes do endividamento na indústria sucroenergética brasileira: análise a partir das teorias de estrutura de capital. Organizações Rurais \& Agroindustriais, v. 18, n. 2, 2016.

MUKHERJEE, S.; MAHAKUD, J. Are trade-off and pecking order theories of capital structure mutually exclusive. Journal of Management Research, v. 12.1, p. 41-55, 2012.

MYERS, S.; MAJLUF, N. Corporate financing and investment decisions when firms have information that investors do not have. Journal of Financial Economics, v. 13.2, p. 187-221. 1984.

MYERS, S. The capital structure puzzle. The Journal of Finance, v. 39.1, p. 575592, 1984.

NAKAMURA, W. et al. Determinantes de estrutura de capital no mercado brasileiro - análise de regressão com painel de dados no período 1999-2003. Revista de Contabilidade Financeira, n. 44, p. 72-85, maio/ago. 2007.

PALACÍN-SÁNCHEZ, M.; RAMÍREZ-HERRERA, L.; DI PIETRO, F. Capital structure of SMEs in Spanish regions. Small Business Economics, v. 41.2, p. 503519, 2013. 
PEROBELLI, F.; FAMÁ, R. Fatores determinantes da estrutura de capital: aplicação a empresas de capital aberto no Brasil. Revista de Administração, v. 37, n. 3, p. 33-46, 2002.

RAJAN, R.; ZINGALES, L. What do we know about capital structure? Some evidence from international data. The Journal of Finance, v. 50.5, p. 1421-1460, 1995.

SERRASQUEIRO, Z.; CAETANO, A. Trade-Off Theory versus Pecking Order Theory: capital structure decisions in a peripheral region of Portugal. Journal of Business Economics and Management, v. 16.2, p. 445-466, 2015.

SERRASQUEIRO, Z.; NUNES, P. Is age a determinant of SMEs' financing decisions? Empirical evidence using panel data models. Entrepreneurship Theory and Practice, v. 36.4, p. 627-654, 2012.

SHEIKH, N.; QURESHI, M. Crowding-out or shying-away: impact of corporate income tax on capital structure choice of firms in Pakistan. Applied Financial Economics, v. 24.19, p. 1249-1260, 2014.

SHYAM-SUNDER, L.; MYERS, S. Testing static trade off against pecking order models of capital structure. Journal of Financial Economics, v. 51.2, p. 219-244, 1999.

TITMAN, S.; WESSELS, R. The determinants of capital structure choice. The Journal of Finance, Salt Lake City, v. 43, i. 1, p. 1-19, 1988.

YOTI, L.; SHENG-CHU, S.; WEN-CHENG, L. Capital structure timing in markets with different characteristics. The International Journal of Business and Finance Research, v. 6.3, p. 53-66, 2012.

\section{Como citar este artigo:}

\section{ABNT}

CAMFIELD, Claudio Eduardo Ramos et al. A estrutura de capital de empresas de pequena dimensão em Portugal: uma abordagem segundo as Teorias do Trade-off e da Pecking-order. RACE, Revista de Administração, Contabilidade e Economia, Joaçaba: Ed. Unoesc, v. 17, n. 1, p. 365-388, jan./abr. 2018. Disponível em: <http:// editora.unoesc.edu.br/index.php/race>. Acesso em: dia/mês/ano. 


\section{APA}

Camfield, C. E. R., Freitas, G. M. da S., Correia, M. R. F., \& Serrasqueiro, Z. (2018). A estrutura de capital de empresas de pequena dimensão em Portugal: uma abordagem segundo as Teorias do Trade-off e da Pecking-order. RACE, Revista de Administração, Contabilidade e Economia, 17(1), 365-388. Recuperado em dia/mês/ ano, de http://editora.unoesc.edu.br/index.php/race 
